\title{
Clinical genetics of melanoma
}

\author{
T Debniak \\ From Annual Conference on Hereditary Cancers 2009 \\ Szczecin, Poland. 10-11 December 2009
}

Malignant melanoma (MM) represents one of the most aggressive neoplasms and its frequency is increasing rapidly. Increased melanoma risk among relatives of MM patients and familial aggregations of this malignancy point at genetic predisposition as an important factor of MM pathogenesis. The genetic basis of MM is complex and appears to involve multiple genes. CDKN2A is regarded as the major MM susceptibility gene. In the Polish population common CDKN2A variant (A148T) increases significantly melanoma risk regardless of the cancer family history. Mutations of other high risk genes, ARF and CDK4 are extremely rare. The higher rates of $C D K N 2 A / p 16$ mutations can be detected only in rare cases characterized by:

1) occurrence of three or more primary melanomas,

2) patients with three or more melanomas in aggregate among first or second degree relatives,

3) families with the presence of three or more cases of melanoma and/or pancreatic cancer on the same side of the family.

It is thus necessary to perform association studies focused on identifying genetic markers that could be used in identifying patients with a high risk of MM. List of other genes that carry mutations, which are believed to be associated with moderate MM risk include XPD, MC1R, BRCA2. Newest genome-wide association study identified three loci associated with melanoma risk: 16q24, 11q14-q21, 9p21.

The management with individuals being at increased MM risk involves clinical screening according to carefully planned surveillance schedule and early treatment of MM tumour. The appropriate management may reduce morbidity and mortality. Genetic testing and clinical evaluation should be performed, and family

International Hereditary Cancer Center, Pomeranian Medical University, Szczecin, Poland history should be obtained in all patients affected with $\mathrm{MM}$, also in those with apparently sporadic tumours.

Published: 1 June 2011

doi:10.1186/1897-4287-9-S2-A10

Cite this article as: Debniak: Clinical genetics of melanoma. Hereditary Cancer in Clinical Practice 2011 9(Suppl 2):A10. and take full advantage of:

- Convenient online submission

- Thorough peer review

- No space constraints or color figure charges

- Immediate publication on acceptance

- Inclusion in PubMed, CAS, Scopus and Google Scholar

- Research which is freely available for redistribution 